\title{
Preparation and Characterization of a Tumor-Targeting Dual-Image System Based on Iron Oxide Nanoparticles Functionalized with Folic Acid and Rhodamine
}

\author{
Alejandra Ancira-Cortez, ${ }^{1}$ Enrique Morales-Avila, ${ }^{1}$ \\ Blanca E. Ocampo-García, ${ }^{2}$ Carlos González-Romero, ${ }^{1}$ Luis A. Medina,, ${ }^{3,4}$ \\ Gustavo López-Téllez, ${ }^{5}$ and Erick Cuevas-Yáñez ${ }^{5}$ \\ ${ }^{1}$ Facultad de Química, Universidad Autónoma del Estado de México, 50120 Toluca, MEX, Mexico \\ ${ }^{2}$ Instituto Nacional de Investigaciones Nucleares, Departamento de Materiales Radiactivos, 52750 Ocoyoacac, MEX, Mexico \\ ${ }^{3}$ Instituto de Física, Universidad Nacional Autónoma de México, 04510 Ciudad de México, Mexico \\ ${ }^{4}$ Unidad de Investigación Biomédica en Cáncer INCan-UNAM, Instituto Nacional de Cancerología, 14080 Ciudad de México, Mexico \\ ${ }^{5}$ Centro Conjunto de Investigación en Química Sustentable UAEM-UNAM, Universidad Autónoma del Estado de México, \\ Toluca, MEX, Mexico \\ Correspondence should be addressed to Enrique Morales-Avila; emoralesav@uaemex.mx
}

Received 25 January 2017; Accepted 2 April 2017; Published 30 April 2017

Academic Editor: Murtaza Bohra

Copyright (C) 2017 Alejandra Ancira-Cortez et al. This is an open access article distributed under the Creative Commons Attribution License, which permits unrestricted use, distribution, and reproduction in any medium, provided the original work is properly cited.

Cancer is one of the diseases with most deaths worldwide, around 8.2 million annually. For this reason, several treatments and diagnostic tools have been investigated and developed over the past decades. Among them, a dual-image system has been developed to achieve and enhance the detection of cancer, which has not been done with systems currently available. The present study describes the preparation of a dual-image targeting system composed of magnetic iron oxide nanoparticles functionalized with folic acid and rhodamine; nanoparticles synthesis was achieved by a coprecipitation method; the functionalization was carried out by a carbodiimide with folic acid and/or the rhodamine isothiocyanate; conjugates were characterized by spectrometric techniques; toxicity was measured by cell proliferation assay on HeLa cells using progressive concentrations of functionalized nanoparticles. Cellular uptake assay was carried out by competitive assay on HeLa cells. Iron oxide magnetite nanoparticles, modified with folic acid and rhodamine, were successfully synthetized with a particle size lower than $20 \mathrm{~nm}$ (TEM), EDS, HRTEM, and XDR showed highly crystalline $\mathrm{Fe}_{3} \mathrm{O}_{4}$ nanoparticles. Folic acid and rhodamine were conjugated with high efficiency. A significant selectivity and uptake, facilitated by surface modification of iron oxide nanoparticles with folic acid, were demonstrated. The multifunctional system showed suitable physicochemical and biological properties for cell targeting through folate receptors.

\section{Introduction}

Molecular imaging comprises the noninvasive monitoring of functional and spatiotemporal processes at cellular, subcellular, or molecular levels in humans and other living systems. Although molecular imaging has existed for decades, recent advances in molecular and cell biology, imaging technology, and material sciences have greatly increased its power and potential as specific and sensitive medical tools [1].

Nanoparticles (NPs) are submicron moieties with diameters ranging from 1 to $100 \mathrm{~nm}$, depending on their intended purpose, which have many novel physical and chemical properties that are not present in the atom nor the bulk counterpart, related to the dimensions and shape, as well as morphology [2, 3]; NPs have been used in many different biological and medical applications as key components for imaging probe design [4-7].

Iron oxide nanoparticles (IONPs) of magnetite type $\left(\mathrm{Fe}_{3} \mathrm{O}_{4}\right)$ have desirable physical and biochemical characteristics (e.g., superparamagnetism, high coercivity, low Curie temperature $\left(T_{C}\right)$, high magnetic susceptibility, chemical stability in physiological conditions, high saturation fields, 
biocompatibility, and biodegradable and nontoxic nature), which make them useful in the diagnosis and treatment in the oncology field [8-10].

A desirable molecular imaging probe must be able to reach specific targets with high affinity, sensitivity, and suitable biodistribution properties. Nanoparticle-based molecular imaging probes can be functionalized or modified due to their high surface area-to-volume ratio, by bioactive molecules, typically through chemical coupling via amide or ester bonds in order to reach a target site. Some of the molecules used as targeting elements include small ligands, antibodies and derivatives, aptamers and other nucleic acids, polyunsaturated fatty acids, peptides, and proteins [2, 11-13]. Furthermore, surface modification can include fluorescence dyes, genes, or drugs, to provide multimodal functionalities [3].

Folic acid (FA) is a water-soluble vitamin, can be easily conjugated to supramolecular and macromolecular structures, and has been used as a vector for cancer cells targeting due to its high affinity $\left(K_{d} \sim 10^{-10} \mathrm{mM}\right)$ for its corresponding folate receptors (FRs: $\mathrm{FR}_{\alpha}, \mathrm{FR}_{\beta}$, and $\mathrm{FR}_{\gamma}$ ), to mediate cellular uptake of FA [12, 14-18].

FRs are overexpressed in a large number of cancer cells and are positively associated with tumor stage and histologic grade (e.g., ovarian cancer, endometrial cancer, kidney cancer, colorectal cancer, lung cancer, breast cancer, brain cancer, and myeloid leukemia); FRs provide a special marker that distinguishes cancer cells from normal cells, as these exhibit limited expression, are largely restricted to those important for embryonic development (e.g., placenta and neural tubes), and present low levels in folate resorption through kidney and lung. It has been reported that folate conjugation to the IONPs enhances the cellular uptake to target cells, improving therapeutic efficacy [12, 17-21].

Rhodamine B isothiocyanate, on the other hand, is a fluorophore that belongs to the xanthene dyes family. Due to its photophysical properties and excellent photostability, it is used as fluorescence probes for imaging sensor techniques. Optical imaging allows noninvasive drug visualization in cells and tissues in order to understand molecular processes in real time. Specifically, it has been reported that several MNPs (magnetic nanoparticles) can be used as dual-modality imaging probes, in nuclear and optical fluorescence imaging which is the case of IONPs [22-25].

Therefore, we aimed to develop a tumor-targeting dualimage system based on IONPs with folic acid as a vector and rhodamine isothiocyanate as an imaging agent, primarily designed for noninvasive monitoring, in order to acquire high-quality targeted images without cytotoxicity to normal cells.

\section{Materials and Method}

All chemicals were of analytical grade from commercial sources used without further purification. Ferric chloride hexahydrate $\left(\mathrm{FeCl}_{3} \cdot 6 \mathrm{H}_{2} \mathrm{O}\right)$, ferrous chloride tetrahydrate $\left(\mathrm{FeCl}_{2} \cdot 4 \mathrm{H}_{2} \mathrm{O}\right)$, folic acid, $N$-(3-dimethylaminopropyl)- $N^{\prime}$ ethylcarbodiimide hydrochloride (EDC), 4-(dimethylamino)pyridine (DMAP), 2-aminoethylphosphonic acid (2$\mathrm{AEP})$, and rhodamine $\mathrm{B}$ isothiocyanate mixed isomers
(RITC) were purchased from Sigma-Aldrich ${ }^{\circledR}$ Chemical Co. (St. Louis, MO, USA). Folate-free RPMI-1640 medium, bovine fetal serum, $\mathrm{NaHCO}_{3}$, antibiotic-antimycotic solution $(100 \mathrm{x})$ containing penicillin, streptomycin, and amphotericin, and other chemicals and solvents were of reagent grade. The HeLa cell line was obtained from the National Institute of Cancerology, Mexico.

2.1. Synthesis of Magnetic Iron Oxide Nanoparticles (IONPs) and Surface Activation. Bare magnetic iron oxide nanoparticles were synthesized by an alkaline coprecipitation of $\mathrm{Fe}^{3+}$ and $\mathrm{Fe}^{2+}$, in agreement with Banerji et al., [26]. For surface activation, a freshly prepared aqueous solution of 2-AEP $(1 \mathrm{mM})$ was added to $4 \mathrm{mM}$ of a colloidal suspension of NPs with sonication using a high-intensity ultrasonic probe during an hour. Then, the resulting nanoparticle suspension was stirred vigorously at $25^{\circ} \mathrm{C}$ for $24 \mathrm{~h}$. The particles were then washed with deionized water three times via magnetic decantation and finally dried by evaporation at $37^{\circ} \mathrm{C}$. Samples were stored for posterior use (see Figure 1(a)).

2.2. Synthesis of the Iron Oxide Folate Conjugate (IONPs-FA). Magnetic iron oxide NPs were modified with folic acid (FA) using a solution of FA $(2.5 \mathrm{mM})$ in $5 \mathrm{~mL}$ of dichloromethane (DCM). The solution was mixed with an ethanolic solution of $N$-(3-dimethylaminopropyl)- $N^{\prime}$-ethylcarbodiimide (EDC) (75 mM) and 4-(dimethylamino) pyridine (DMAP) $(15 \mathrm{mM})$. Afterwards, the solution was sonicated using a high-intensity ultrasound probe during $2 \mathrm{~h}$. The solution was allowed to stand overnight. Posteriorly, the solution was stirred vigorously at $25^{\circ} \mathrm{C}$ during $24 \mathrm{~h}$, and the IONPs were recovered and washed via magnetic decantation, using ethanol and deionized water as diluents (see Figure 1(b)). The product was stored for use in the subsequent steps.

2.3. Synthesis of Amine-Functionalized Magnetofluorescent RITC Nanoparticles (IONPs-RITC). An aqueous suspension of 2-AEP-functionalized INOPs $(\sim 25 \mathrm{mg})$ was prepared and homogenized using a high-intensity ultrasound probe for $10 \mathrm{~min}$. Then, RITC $(0.25 \mathrm{mM})$ was dissolved in $10 \mathrm{~mL}$ of DMSO, and the solution of RITC was added dropwise to the aqueous suspension. Once the mixture was complete, the resulting suspension was sonicated for an hour in the dark. Nanoparticles were recovered by magnetic concentration and washed thoroughly with deionized water; samples were stored for posterior use.

2.4. Synthesis of Iron Oxide Folate Fluorescent Nanoparticles (FA-IONPs-RITC). To create the multifunctional system, $\sim 1.3 \mathrm{mg}$ of RITC $(0.25 \mathrm{mM})$ was dissolved in $10 \mathrm{~mL}$ of DMSO. Then, the solution was added dropwise in the dark to the previous iron oxide folate suspension (IONPs-FA). The resulting suspension was sonicated during an hour. After that, the system was thoroughly washed with deionized water via magnetic concentration and stored for posterior use (see Figure 1(c)).

2.4.1. Size and Morphology. Nanoparticles were analyzed by TEM in a JEOL JEM 2010 HT microscope operating at 
<smiles>OC1C(O)C(O)C(O)C(O)C(O)C1O</smiles>

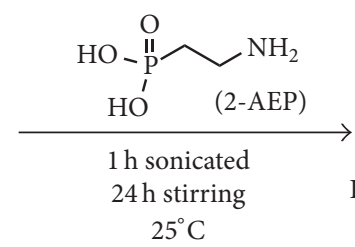

$25^{\circ} \mathrm{C}$

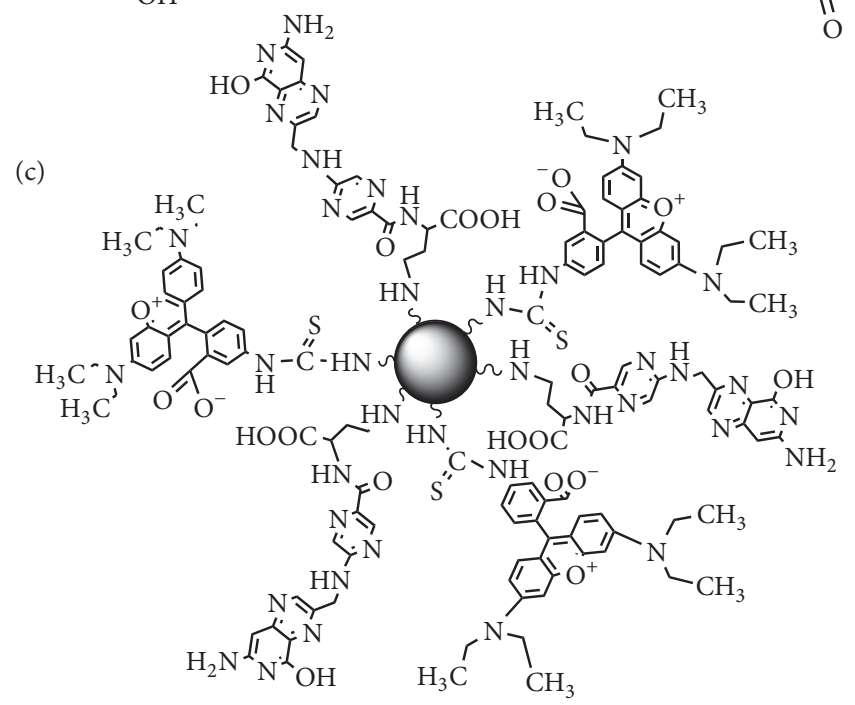

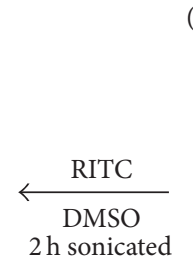

(b)

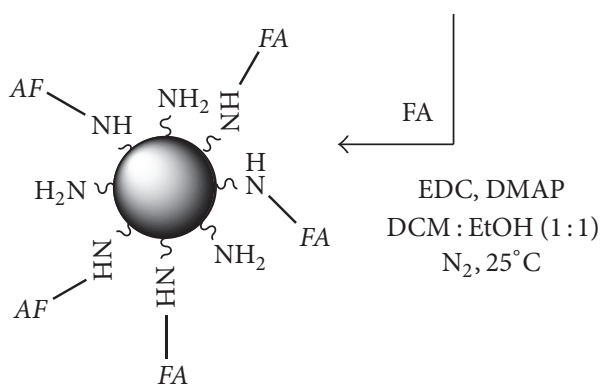

FA-IONP-RITC

Magnetofluorescent iron oxide folate nanoparticles<smiles>Nc1cc2ncc(Nc3cnc(C(=O)NC(CCC(=O)O)C(=O)O)nc3)nc2nc1O</smiles>

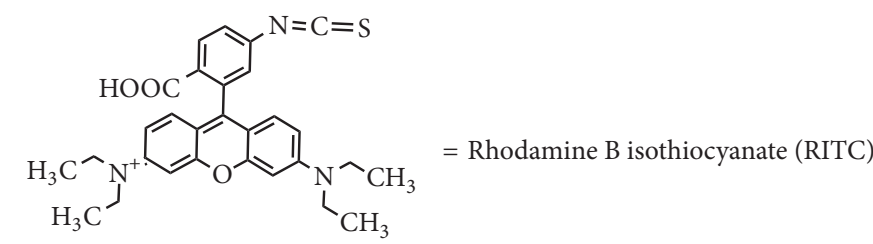

FIGURE 1: Schematic synthesis of amine-functionalized magnetite nanoparticles: (a) the surface of IONPs was modified with 2-AEP to form an amine-functionalized phosphonate monolayer, and (b) folic acid/rhodamine isothiocyanate were conjugated through the carbodiimide reaction, in order to obtain FA-IONPs-RITC.

$200 \mathrm{kV}$ in order to observe the two-dimensional relative size and morphology of nanoparticles. Samples were prepared for analysis by evaporating a drop of aqueous product on a carbon-coated TEM copper grid. At least 1000 nanoparticles were measured using the Image J software, to determine the mean diameter of nanoparticles.

2.4.2. X-Ray Diffraction. X-ray diffraction (XRD) patterns of naked iron oxide cores were recorded on a powder diffractometer Bruker D8 Advance to characterize the crystallite type. Sample was concentered with magnetic decantation and dried by evaporation at room temperature and high vacuum. After that, sample was removed and desiccated thoroughly over dried silica gel and posteriorly screened with the goniometer at $2 \theta$ angles from $5^{\circ}$ to $80^{\circ}$ at a step width of $0.03^{\circ}$.

2.4.3. Infrared Spectroscopy. The IR spectra were acquired from vacuum-dried samples on a PerkinElmer System 2000 spectrometer with an ATR platform (Pike Technologies) by applying the Attenuated Total Reflection Fourier Transform Infrared (ATR-FTIR) spectroscopy with a $4 \mathrm{~cm}^{-1}$ resolution, 40 scans, and operating range at $4000-40 \mathrm{~cm}^{-1}$.

2.4.4. UV-Vis Studies. The absorption spectra, in the range of 200-700 nm, were obtained through a Thermo Genesys 10S spectrometer using a $1 \mathrm{~cm}$ quartz cuvette.

2.4.5. Fluorescence Spectroscopy. The emission fluorescence spectra, in the range of $450-750 \mathrm{~nm}$, were obtained through a Horiba Jobin Yvon Spectrofluorometer (Fluoromax-P) with dual excitation and emission monochromators in a wavelength range between 350 and $800 \mathrm{~nm}$. Nanoparticles were measured with a $\lambda_{\text {exc }}$ of $398 \mathrm{~nm}$ using a $1 \mathrm{~cm}$ cuvette. Three-/0.5-second scans were acquired.

2.4.6. Determination of the Concentration of FA Conjugated over the Surface of the IONPs. The number of FA molecules attached per nanoparticle was calculated by UV-Vis spectroscopy using different FA concentration (2.5 to $10.0 \mathrm{mM}$ ), 
as in the carbodiimide reaction described in the experimental section. The concentration was calculated using the prepared standard curve $\left(r^{2}=0.9997\right.$, with excellent linearity from $0.0125 \mathrm{mM}$ to $15 \mathrm{mM}$ ). The experiments were conducted in triplicate.

2.4.7. Concentration of RITC Conjugated over the Surface of the IONPs. Conjugation was determined by titration using $0.0125 \mathrm{mM}, 0.0375 \mathrm{mM}$, and $0.0625 \mathrm{mM}$ RITC, employing the synthesis method described in the experimental section. Samples were washed with purified and deionized water, and the corresponding nanoparticles were measured by UV-Vis spectroscopy, calculating the concentration using the prepared rhodamine isothiocyanate standard curve $\left(r^{2} \geq\right.$ 0.9975, with excellent linearity from $0.0033 \mathrm{mM}$ to $0.0673 \mathrm{mM})$. The experiments were conducted in triplicate.

2.4.8. Cell Proliferation Studies/Nanoparticle-Induced Cytotoxicity. HeLa (human cervix adenocarcinoma) cells $\left(1 \times 10^{4}\right.$ cells/well) were seeded onto a 96-well plate and cultured in $200 \mu \mathrm{L}$ of folate-free RPMI medium containing 10\% FBS, 100 units $\mathrm{mL}^{-1}$ penicillin, $100 \mu \mathrm{g} \mathrm{mL}^{-1}$ streptomycin, and $0.25 \mu \mathrm{g} \mathrm{mL}^{-1}$ amphotericin $\mathrm{B}$ at $37^{\circ} \mathrm{C}$ in a humidified $5 \%-\mathrm{CO}_{2} / 95 \%$-air atmosphere and incubated for $24 \mathrm{~h}$. The cells were treated with $20 \mu \mathrm{L}$ of different FA-IONPs-RITC nanoparticle concentrations $\left(0.5 \mathrm{mg} \mathrm{mL}^{-1}, 0.25 \mathrm{mg} \mathrm{mL}^{-1}\right.$, $0.125 \mathrm{mg} \mathrm{mL}^{-1}$, and $0.0625 \mathrm{mg} \mathrm{mL}^{-1}$ ) and $180 \mu \mathrm{L}$ of media culture was added and incubated for $24 \mathrm{~h}$ at $37^{\circ} \mathrm{C}$ in a humidified incubator maintained at 5\% $\mathrm{CO}_{2} / 95 \%$ air atmosphere. Thereafter, cells were washed thoroughly with PBS to remove the noninternalized nanoparticles. Cell viability was evaluated using a crystal violet staining. Untreated cells served as $100 \%$ viable cells.

2.4.9. Cellular Uptake. Nanoparticle uptake by HeLa cells was evaluated using $5 \times 10^{5}$ cells/well seeded onto 24 -well plates and cultured in a total volume of $2000 \mu \mathrm{L}$ of folatefree RPMI medium containing $10 \% \mathrm{FBS}, 100$ units $\mathrm{mL}^{-1}$ penicillin, $10 \mu \mathrm{g} \mathrm{mL}^{-1}$ streptomycin, and $0.25 \mu \mathrm{g} \mathrm{mL}^{-1}$ amphotericin $\mathrm{B}$ at $37^{\circ} \mathrm{C}$ in a humidified $5 \%-\mathrm{CO}_{2} / 95 \%$-air atmosphere at $37^{\circ} \mathrm{C}$ in a humidified incubator maintained at $5 \% \mathrm{CO}_{2} / 95 \%$ air atmosphere. To test nanoparticle uptake via folate receptors, a group of HeLa cells were pretreated with $500 \mu \mathrm{L}$ of free folic acid $(11 \mathrm{mg} / \mathrm{mL})$ in order to saturate receptors and incubated at $37^{\circ} \mathrm{C}$ for $2 \mathrm{~h}$. After receptor saturation, both blocked and nonblocked HeLa cells were treated with $40 \mu \mathrm{L}$ of IONPs (at a concentration of $0.25 \mathrm{mg} \mathrm{mL}^{-1}$ ) eluted in PBS for $3 \mathrm{~h}$, posteriorly supernatants were collected and measured by UV-Vis spectroscopy at $280 \mathrm{~nm}$, and absorbances were extrapolated to FA calibration curve. Uptake percentage was calculated, using the baseline as untreated cells in the same conditions. The experiment was performed in triplicate. Finally the images for the cellular uptake test were obtained with an inverted confocal microscope, consisting of an Olympus IX80 with a Plan-Neofluar 40x, AxioVert (Carl Zeiss) objective, and an AxioVision software.

\section{Results and Discussion}

3.1. Size and Morphology. The coprecipitation method for obtaining magnetic iron oxide nanoparticles is one of the fastest and easiest methods for this purpose. Nanoparticles were synthetized in a molar ratio of $\mathrm{Fe}^{3+}: \mathrm{Fe}^{2+}$ of $2: 1$. Transmission electron microscopy (TEM) studies of IONPs revealed that the as-synthesized magnetite nanoparticles were closer to a spherical form and were uniform and homogeneous, which corresponds to that previously reported $[26,27]$.

The IONPs were obtained with a mean hydrodynamic diameter of $18.65 \mathrm{~nm} \pm 0.17 \mathrm{~nm}$ (Figure 2(a)). Size distribution showed a monomodal population; the frequency histogram is shown in Figure 2(b). The EDS patterns shown in (Figure 2(c)), diffraction from the samples consisting of fine particles, and the broad ring patterns from crystal planes attributed to $\mathrm{Fe}_{3} \mathrm{O}_{4}$ nanoparticles confirm the nucleus composition. Additionally, crystallographic High Resolution TEM (HRTEM) showed the highly crystalline $\mathrm{Fe}_{3} \mathrm{O}_{4}$ nanoparticles with the lattice fringes, corresponding to (220) and (111) planes of magnetite crystal with lattice spacing of 0.30 and $0.49 \mathrm{~nm}$, respectively.

Evidence of identity and crystal structure was further verified by X-ray diffraction patterns (Figure 3). Intensity signals appeared at defined scattering angles $2 \theta$ with the most prominent ones at $18.26^{\circ}, 30.05^{\circ}, 35.54^{\circ}, 43.11^{\circ}, 53.42^{\circ}$, $56.92^{\circ}, 62.63^{\circ}$, and $73.97^{\circ}$ (Figure 2). The Bragg peaks could be assigned to specific diffraction planes inside the lattice: (111), (220), (311), (400), (422), (511), (440), and (533) corresponding to magnetite $\left(\mathrm{Fe}_{3} \mathrm{O}_{4}\right)$, in agreement with JCPDS (160629).

\subsection{FT-IR Studies}

3.2.1. Iron Oxide Nanoparticles. The Far-IR and FT-IR (Mid) spectra of IONPs obtained showed the characteristic vibrations for the iron oxide material, in its magnetite phase (Figure $4(\mathrm{a})$ ). For the first case $\left(700-40 \mathrm{~cm}^{-1}\right)$, the mediumintense band at $345 \mathrm{~cm}^{-1}$ is attributed to the vibration of the magnetite core. The previously mentioned band has been previously reported to be specific for $\mathrm{Fe}_{3} \mathrm{O}_{4}$ [28]. In the second case, for the medium zone $\left(4500-400 \mathrm{~cm}^{-1}\right)$, the expected vibrational bands were observed at $558 \mathrm{~cm}^{-1}$ and $3256 \mathrm{~cm}^{-1}$. The first one corresponds to the specific $\mathrm{Fe}-\mathrm{O}$ vibration of iron oxide nanoparticles, which confirms the material expected. The band at $3256 \mathrm{~cm}^{-1}$ was assigned to the -OH st vibration groups due to adsorbed water on the surface of the iron oxide nanoparticles [29, 30].

3.2.2. Amino-Modified Nanoparticles. The FT-IR of 2-AEP functionalized IONPs (Figure 4(b)) showed a strong band at $1026 \mathrm{~cm}^{-1}$ from the st vibration related to the overlapping of the signals which correspond to the vibrations of $\mathrm{M}-\mathrm{O}-\mathrm{P}$, $\mathrm{P}=\mathrm{O}$, and the $\mathrm{P}-\mathrm{O}$ bond. The band at $3361 \mathrm{~cm}^{-1}$ corresponds to the $-\mathrm{NH}_{2}$ group st vibration, which is confirmed with the bending scissoring vibration present at $1631 \mathrm{~cm}^{-1}$. These two bands confirm the presence of the amino-terminal groups 

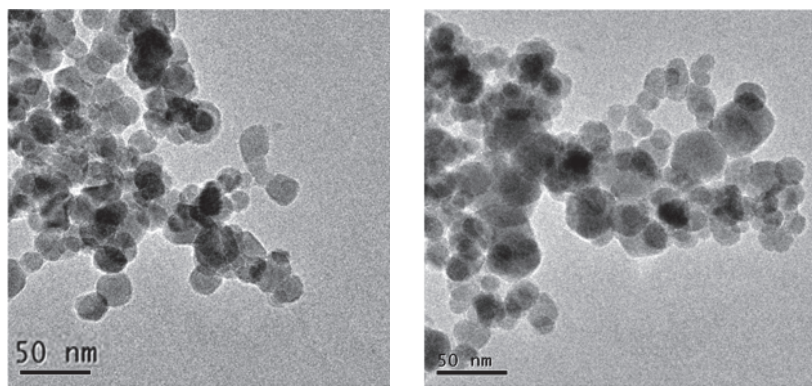

(a)

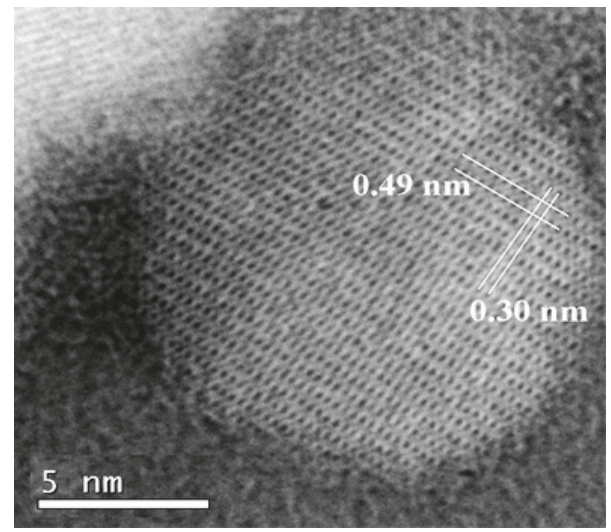

(c)

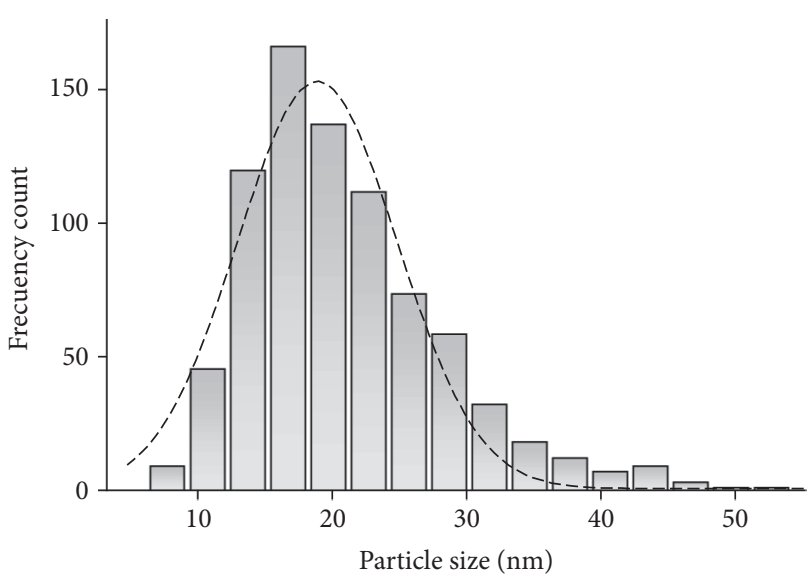

--- IONPs

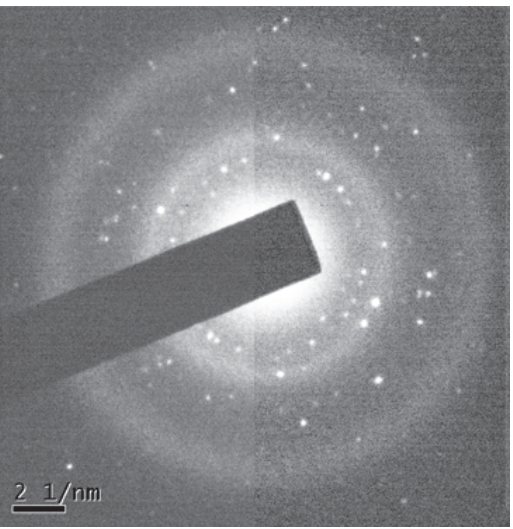

(d)

FIGURE 2: (a) TEM micrograph of unmodified magnetite nanoparticles; (b) particle size distribution (PSD) histogram and adjusted fit function; (c) HRTEM of a fine particle and (d) DR pattern attributed to the diffraction from the crystal planes of $\mathrm{Fe}_{3} \mathrm{O}_{4}$ nanoparticles.

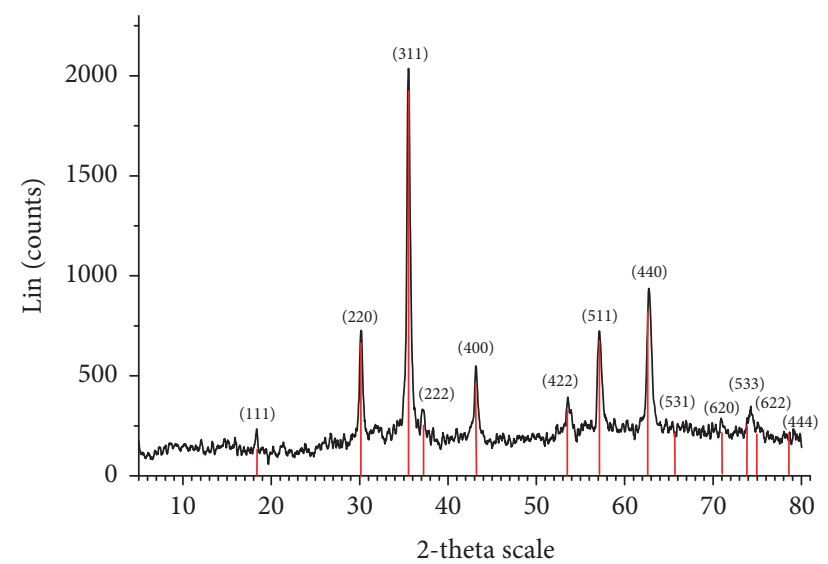

FIGURE 3: XRD pattern of prepared magnetite $\left(\mathrm{Fe}_{3} \mathrm{O}_{4}\right)$ nanoparticles indicative of inverse spinel structure. Significant signals are assignable to diffraction planes (111), (220), (311), (222), (400), (422), (511), (440), and (533).

on the nanoparticle surface, which are necessary for the posterior functionalization. The peak for the magnetite core at $558 \mathrm{~cm}^{-1}$ shifts towards higher wavenumbers, to $570 \mathrm{~cm}^{-1}$.
Also, a significant decrease in the intensity of this band was observed, which indicates the adsorption of phosphonic acids onto the magnetite surface.

3.2.3. IONPs-FA System. In the FT-IR spectrum of folateconjugated nanoparticles (Figure 4(c)), the peak in the range of $3100-3500 \mathrm{~cm}^{-1}$ was assigned to the N-H st vibration from the $-\mathrm{NH}_{2}$ and amine $\mathrm{NH}$ groups from folic acid. At $1648 \mathrm{~cm}^{-1}$, the band present is related to the carbonyl group st vibration from amide and acidic groups, which exhibits less intensity and was shifted to $\sim 1700 \mathrm{~cm}^{-1}$, indicating that folic acid was successfully attached to the IONPs. The bands at $1606 \mathrm{~cm}^{-1}$ and $1548 \mathrm{~cm}^{-1}$ were assigned to the characteristic FA st vibrations (amide II and amide I, resp.), which indicate the successful conjugation to the nanoparticle surface. The presence of the new band at $1530 \mathrm{~cm}^{-1}$ was confirmed from the $s t$ vibration of the amide binding between $\mathrm{Fe}_{3} \mathrm{O}_{4}-\mathrm{NH}_{2}$ $\mathrm{FA}$, which indicates the formation of an extra amide bond attributed to the FA attachment onto the surface of IONPs, as well as the amide bands within the FA structure. Finally, it is important to mention that the vibration from the magnetite 


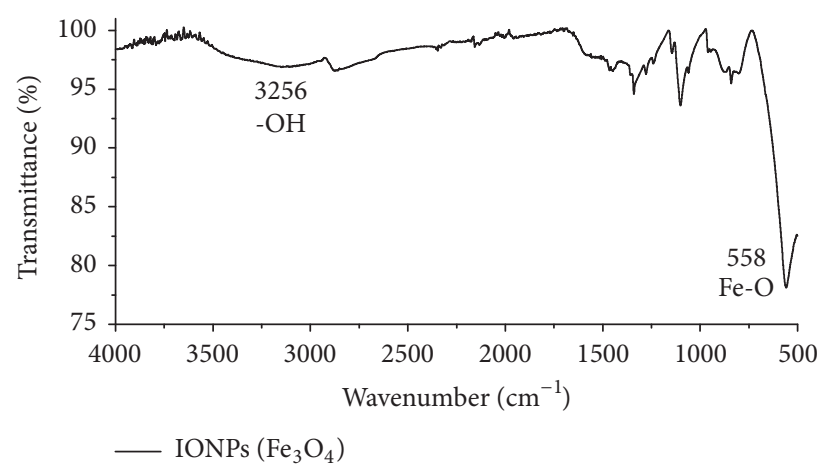

(a)

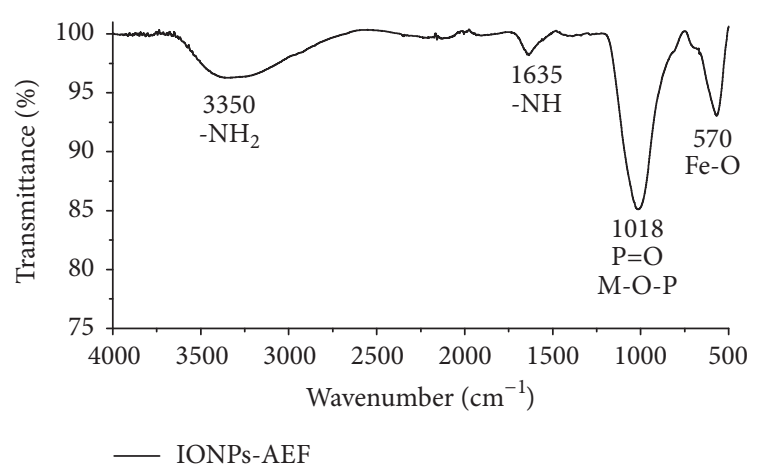

(b)

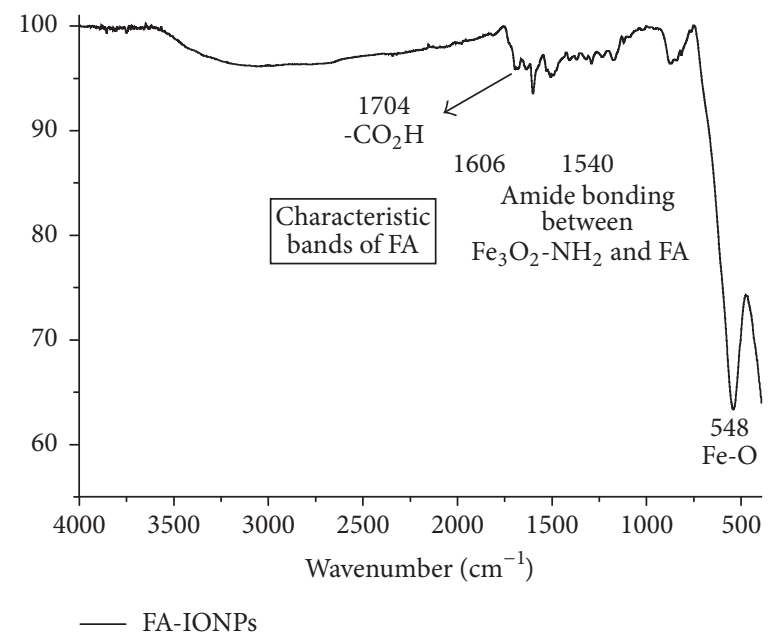

(c)

FIGURE 4: FT-IR spectra of (a) unmodified and amino-functionalized magnetite nanoparticles, (b) iron oxide folate conjugate nanoparticles, and (c) unmodified magnetite nanoparticles in far infrared.

core still appears at $548 \mathrm{~cm}^{-1}$, which suggests that, even with the formation of the conjugate, the core does not suffer any important alteration [18].

3.3. UV-Vis Studies. The UV-Vis spectra from the unmodified magnetite, folic acid conjugate, rhodamine conjugate, folic acid/rhodamine magnetite nanoparticles, folic acid solution, and rhodamine solution have been depicted in the Figure 5(a). The magnetite core of the system, in the range 200-700 nm of the UV-Vis spectra, showed a characteristic band around $360 \mathrm{~nm}$ which demonstrated a suitable synthesis. The peak at $\sim 280 \mathrm{~nm}$ was assigned to FA due to the wellknown $\pi-\pi^{*}$ transitions from the pteridine ring moiety in the FA structure [31]. This UV-Vis band is present in the FA aqueous solution at $282 \mathrm{~nm}$ and in the IONPs-FA system at $283 \mathrm{~nm}$. In the case of the FA-IONPs-RITC system, in which FA is also present, the band still appeared at $283 \mathrm{~nm}$ [29].

On the other hand, for the UV-Vis spectra for the same systems but focus on the RITC molecules, a band around $550 \mathrm{~nm}$ is present, which has been reported in previous works (536 nm for IONPs-RITC and $580 \mathrm{~nm}$ for FA-IONPs-RITC) [32], and although it is broad, the maximum absorption occurs in the same region.
3.4. Fluorescence Studies. In Figure 5(b), the fluorescence emission spectra from magnetite, folic acid conjugate, rhodamine conjugate, folic acid/rhodamine magnetite nanoparticles, folic acid solution, and rhodamine solution have been depicted.

The band around $575 \mathrm{~nm}$ for the fluorescent emission spectra of the systems containing rhodamine (FA-IONPsRITC and IONPs-RITC) and the one for the solution of RITC are in excellent agreement with the previously reported around $570-575 \mathrm{~nm}[33,34]$. The differences in the band are due to the chemical environment, and the low intensity is due to the quantity employed in the synthesis procedure (being less than $0.1 \%$ of the total system).

For the systems with FA, either FA-IONPs-RITC or IONPs-AF, the emission spectra presented a common band at $545 \mathrm{~nm}$. In the case of FA-IONPs-RITC, a second band appeared at $579 \mathrm{~nm}$ that corresponds to the RITC molecule previously described. For the band at $545 \mathrm{~nm}$, according to previous studies, FA could be present in two forms (basic and acid), due to the pteridine ring moiety. In the emission spectra, the alkaline form used to have a band between 300 and $400 \mathrm{~nm}$ and another band in the $230-290 \mathrm{~nm}$ range with higher absorption coefficients than their acid form. On the 


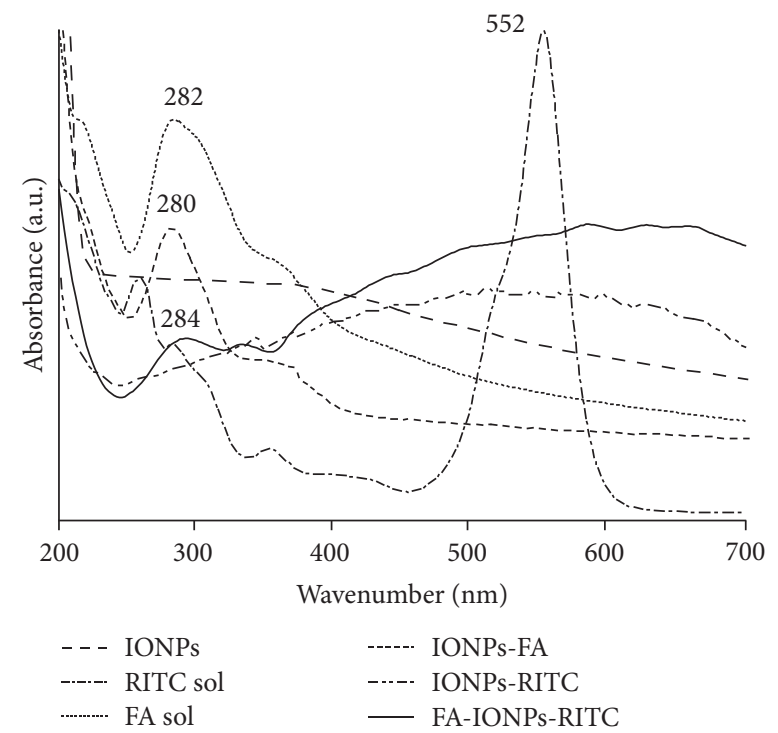

(a)

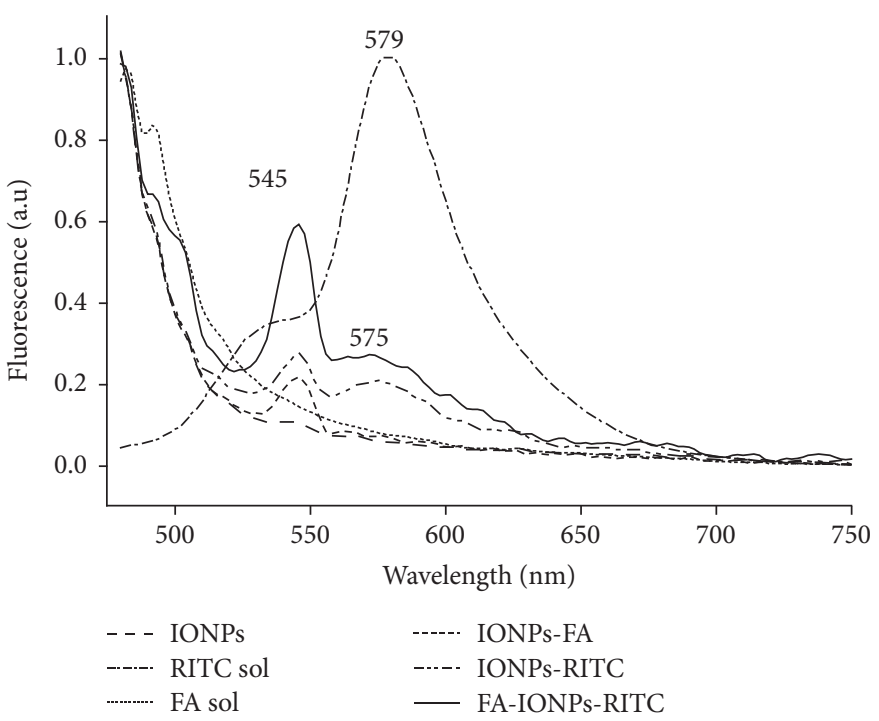

(b)

FIGURE 5: (a) UV-Vis spectra of unmodified magnetite, folic acid conjugate, rhodamine conjugate, folic acid/rhodamine magnetite nanoparticles, folic acid solution, and rhodamine solution. (b) Fluorescence emission spectra of magnetite, folic acid conjugate, rhodamine conjugate, folic acid/rhodamine magnetite nanoparticles, folic acid solution, and rhodamine solution.

TABLE 1: Determination of concentration of FA and RITC conjugated over the IONPs' surface.

\begin{tabular}{lccccc}
\hline $\begin{array}{l}\text { Initial [FA] } \\
{\left[\mathrm{mg} \mathrm{mL}^{-1}\right]}\end{array}$ & $\begin{array}{c}\text { \% FA in IONPs' surface } \\
{[\%]}\end{array}$ & $\begin{array}{c}\text { FA in IONPs' surface } \\
{\left[\mathrm{mg} \mathrm{mL}^{-1}\right]}\end{array}$ & $\begin{array}{c}\text { Initial [RITC] } \\
{\left[\mathrm{mg} \mathrm{mL}^{-1}\right]}\end{array}$ & $\begin{array}{c}\text { \% RITC in IONPs' } \\
\text { surface }[\%]\end{array}$ & $\begin{array}{c}\text { RITC in IONPs' surface } \\
{\left[\mathrm{mg} \mathrm{mL}^{-1}\right]}\end{array}$ \\
\hline 4.4 & 98.8 & 4.3 & 0.75 & 96.8 & 0.72 \\
3.8 & 98.3 & 3.7 & 2.25 & 96.9 & 2.18 \\
3.2 & 98.2 & 3.1 & 3.75 & & 3.63 \\
2.6 & 98.0 & 2.5 & & \\
2.2 & 97.7 & 2.1 & & \\
1.0 & 96.0 & 0.9 & & & \\
\hline
\end{tabular}

other hand, the complete molecule of FA usually presents two bands (at $255 \mathrm{~nm}$ and $285 \mathrm{~nm}$ ) in its alkaline form and an overlapping of the same for the acid form, resulting in a unique band at $285 \mathrm{~nm}$.

Considering this and assuming that the system conjugation was carried out according to what is previously proposed, it is possible to suggest that the pteridine moiety is exposed on system surface. Thus, with the fluorescence studies, it was possible to observe a relative increment of the band at $545 \mathrm{~nm}$, which corresponds to the alkaline form, indicating, in that way, the correct and suitable system conjugation. However, the magnetite core presented a lower intensity band in the same region $(\sim 545 \mathrm{~nm})$, so it is possible to suggest that, in the FA-IONPs-RITC and IONPs-RITC systems, a contribution of both compounds (IONPs and FA) existed in order to increase the intensity of the band in that wavelength. As for the IONPs-RITC system, there was no FA (with its pteridine ring moiety), which can cause the appearance of a band.

3.5. FA Conjugated over the IONPs' Surface. In accordance with the percentages obtained from analysis, it was possible to observe that, even at the lowest initial concentration of
FA, $a>95 \%$ of FA in IONPs surface was reached. Also was important the fact that the reaction had a maximal saturation point with $a$ concentration $>5.0 \mathrm{mM}$, where the percentages were over $98 \%$. These data results were important to optimize the quantities of FA in the final system. In Table 1, the concentrations of FA employed and the percentage of conjugation over the nanoparticle surface are shown.

3.6. RITC Conjugated over the IONPs' Surface. The results demonstrate that, even at the lowest initial concentration of RITC, $a>95 \%$ was conjugated in IONPs surface. The saturation of the system for this specific case was reached even with the lowest initial concentration employed, where the percentages were over $96 \%$. These data results were important to optimize the quantities of RITC in the final system. In Table 1, the RITC concentrations and the conjugation percentage are shown.

Magnetite nanoparticles were successfully prepared in accordance with previous reports using a chemical coprecipitation method in a basic medium, obtaining spheroidal forms with nanometric size [26]. The amino-modified nanoparticles were used as precursor, the functionalization was carried 
out using a derivative of phosphonic acid that undergoes easy formation of a self-assembled, strongly organic monolayer on the nanoparticle surface, and established mechanisms are the chemisorption of 2-AEP on INOPs for the introduction of polar functional groups onto the surface [27]. This coating allows further functionalization by chemical reactions [2]. Several studies have reported that phosphonates and phosphates bind efficiently to the iron oxide nanoparticle surface and can be useful as potential alternatives to link fatty acids or other functional groups. Also, they have good biocompatibility and a high capacity to form strong complexes with transition metals in aqueous solution and show suitable affinity for the metal oxide surface $[2,35]$; additionally, a significant increase on colloidal and chemical stability was observed preventing nanoparticle oxidation processes.

Considering that colloidal stability in an aqueous and physiological medium is one of the most important issues related to the biomedical applications of nanoparticles, these polar functional groups render nanoparticles thermodynamically stable against aggregation and keep them well-dispersed in aqueous media. Furthermore, this system facilitates conjugation with a variety of molecules through sulfhydryl, carboxyl, anhydride, or imine groups, allowing easy manipulation of the surface functionality [35].

The molecular imaging techniques provide a reliable methodology to monitor and record the presence, location, and extent of diseases, although methods such as computed tomography and magnetic resonance imaging have been primary tools for cancer diagnostic, the introduction of new criteria and recommendations for the assessment of an adequate diagnostic, and measure of progression disease, promoting the development of bimodal targeted contrast agents for the detection of molecular markers with both MRI and fluorescence imaging.

In our case, the formation of magnetofluorescent nanoparticles was achieved through a covalent immobilization of rhodamine B isothiocyanate (RITC) on the particle surface, by means of a thiourea linkage through a nucleophilic addition of surface-pendent amine to isothiocyanate groups, to which primary amino groups of suitable organic molecules can be covalently linked, forming the magnetic fluorescent carrier, in this particular case $[22,36]$.

To achieve specificity and cell receptor selectivity, the magnetite nanoparticles were functionalized with folic acid. The active- $\mathrm{NH}_{2}$ groups present on the amino-functionalized nanoparticle surface were covalently conjugated with FA via activation of the carboxyl groups in its glutamic acid moiety by the carbodiimide method. This method may lead to the formation of two structural isomers, in which FA is linked either through the $\alpha$-carboxyl or through $\gamma$-carboxyl group of its glutamic acid moiety. However, the folate linked via $\gamma$ carboxyl group is formed as the major isomer because it is more prone to this reaction due to its higher reactivity and retains a strong affinity towards its receptor, whereas its $\alpha$ carboxyl derivatives are not recognized as readily [36].

The information obtained with analytical technique suggests that the conjugation of the FA at the surface of the IONPs was carried out successfully, as well as the preparation of the multifunctional system FA-IONPs-RITC.
3.7. Nanoparticle-Induced Cytotoxicity. For the cell viability test, the IONPs exposure time was $24 \mathrm{~h}$ as usual. It is important to note that the highest IONPs concentration employed $\left(0.5 \mathrm{mg} \mathrm{mL}^{-1}\right)$ was lower than concentrations used in other studies with different cell lines but much higher than in many other works with that employed magnetite [37]. According to the results shown in Figure 6(a), there was a significant difference between the lowest $\left(0.0 \mathrm{mg} \mathrm{mL}^{-1}\right)$ and the highest $\left(0.5 \mathrm{mg} \mathrm{mL}^{-1}\right)$ concentrations. Despite this, all treatments showed cell viability higher than $80 \%$. The highest FA-IONPs-RITC concentration $\left(0.5 \mathrm{mg} \mathrm{mL}^{-1}\right)$ showed $82.5 \%$ of viability, which demonstrated the biocompatibility of the multifunctional system.

3.8. Cellular Uptake. The folate-conjugated nanoparticles were found to be distributed within the cytoplasm, suggesting cellular internalization through receptor-mediated endocytosis, instead of adhesion to the cell surface. This study unequivocally establishes that all the iron oxide folate nanoconjugates, developed in the course of this research, are preferentially targeted towards cancer cells and effectively internalized ( $63 \pm 7 \%$ of internalization with respect to $43 \pm 5 \%$ of the blocked group). Also, the results indicated that the system with FA could enhance the intracellular uptake of the IONPs effectively, assuming that FA works as a tumor-targeting ligand, which likely enhances receptormediated endocytosis [31]. Receptor-mediated internalization of nanoparticles by FA receptor in overexpressing cancer cells was further demonstrated using an inverted confocal microscope (Olympus IX80). As was predicted from the cytotoxicity experiments, photomicrographs (taken with an Olympus IX80 inverted confocal microscope and an AxioVision software) clearly showed that cellular structures were well preserved without morphology abnormalities after nanoparticles treatment (see Figure 6(b)).

According to previous reports, a nanoparticle size between 10 and $100 \mathrm{~nm}$ results in systems with a size small enough to avoid the mononuclear phagocyte system (MPS) and to penetrate the capillary body cavities. Also, for medical applications, nanoparticles must conform to a size smaller than $100 \mathrm{~nm}$, at which they possess unique physicochemical and pharmacokinetic characteristics are desirables $[12,38]$.

Generally, once a tumor-targeting ligand conjugate has reached its target receptor, uptake and internalization can occur through receptor-mediated bioevents, mainly receptormediated endocytosis, but phagocytosis and pinocytosis can also contribute to internalization. After endocytosis, most but not all ligand-receptor complexes dissociate in the endosomes and the ligand eventually ends up in the lysosomes, while receptors are often recycled and transported back to the cell surface by transport vesicles [31].

The results of the internalization of magnetic nanoparticles are dependent on two factors: (I) the type of coating and (II) the nanoparticle concentration [31]. In the system designed, FA demonstrated that it can promote tumor cell receptor-mediated internalization [17].

A promising diagnostic imaging methods consist in molecular targeting with exogenous fluorescent agents, 


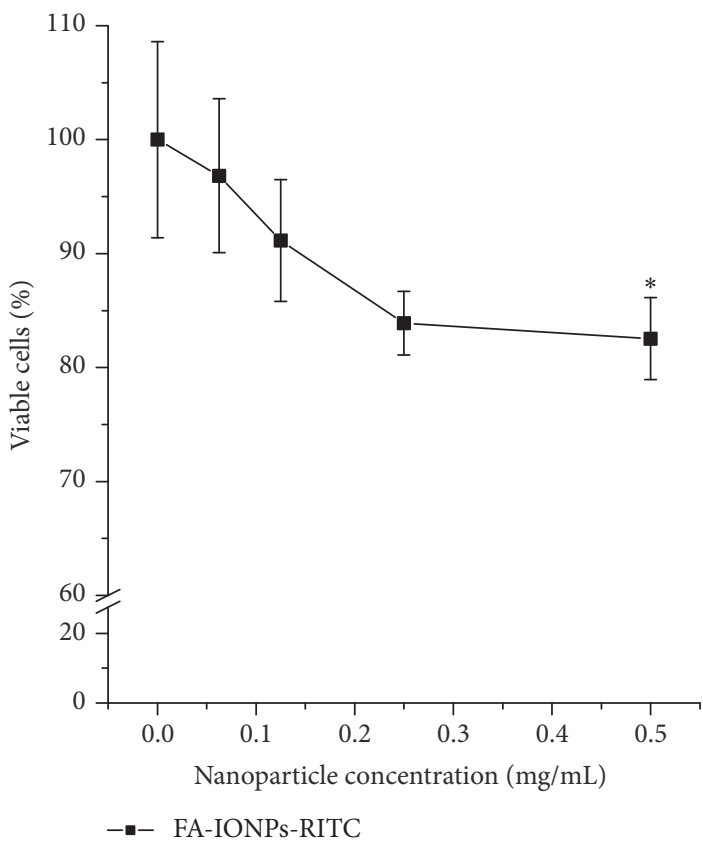

(a)

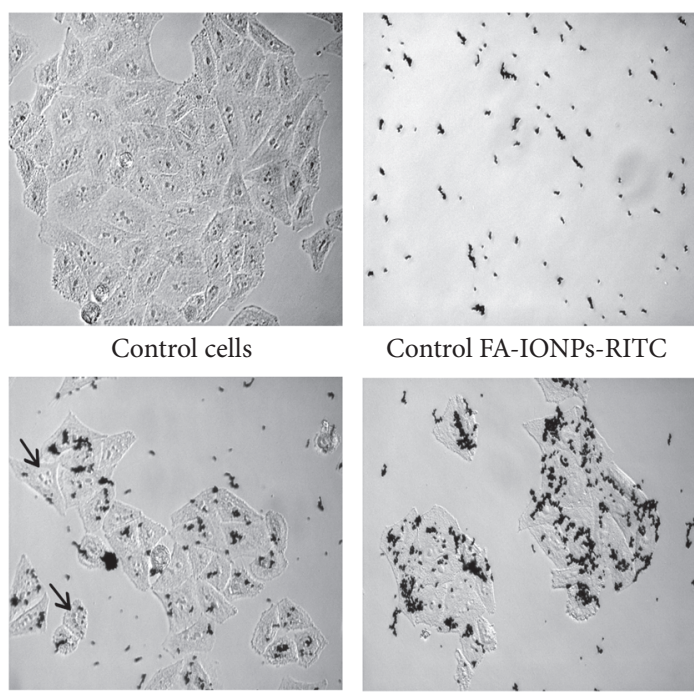

$0.065 \mathrm{mg} / \mathrm{mL}$ FA-IONPs-RITC $0.25 \mathrm{mg} / \mathrm{mL}$ FA-IONPs-RITC

(b)

Figure 6: (a) Effect of folate-rhodamine-conjugated nanoparticles on the HeLa cells viability. Cells incubated with different nanoparticle concentrations for $24 \mathrm{~h}$ at $37^{\circ} \mathrm{C}$ followed by crystal violet staining. ${ }^{*}$ No significant reduction $(p<0.05)$ in cellular viability was observed, the survival rate being higher than $80 \%$, even at the highest nanoparticle concentration. (b) Photomicrographs of cellular uptake test in HeLa cells at two different concentrations. The black arrows show the internalization of the system, which is visible even at low concentrations $\left(0.065 \mathrm{mg} \mathrm{mL}^{-1}\right)$.

employing sensitive targets to report disease and metabolism activity; FA-IONPs-RITC system provides a new class of magnetic/fluorescent nanomaterial. Additionally, fluorescent properties of this conjugate, water soluble, chemically stable, and biocompatible, are desirable features for pharmaceutical purposes. New molecular imaging devices offer the advantage for better spatial resolution and could be applied to extend three-dimensional tissue architecture and dynamic metabolic processes. The development of hybrid contrast agents is based on increasing capabilities to overcome depth tissue limitations and spatial accuracy by image fusion techniques.

\section{Conclusions}

In this work, iron oxide magnetite nanoparticles, modified with folic acid/rhodamine, were successfully synthetized via carbodiimide reaction. This system demonstrated optimal conditions for their use in medical application. The proposed uptake mechanism is through folic acid receptor endocytosis. However, to assure that such mechanism is involved, it is necessary to carry out studies focused on the labeling and tracing of the mechanism through recognition of its receptor. Also, PK studies are crucial in order to elucidate their behavior in vivo and also to prove their magnetic and fluorescent properties.

\section{Conflicts of Interest}

The authors confirm that this article content has no conflicts of interest.

\section{Acknowledgments}

This study was supported by the International Atomic Energy Agency (CRP-F22064, Contract no. 18358) and the Universidad Autónoma del Estado de México, through Project no. 3543/2013CHT. The authors gratefully acknowledge the skillful analytical and instrumental assistance of "Laboratorio Nacional de Investigación y Desarrollo de Radiofármacos, CONACyT."

\section{References}

[1] K. Chen and X. Chen, "Design and development of molecular imaging probes," Current Topics in Medicinal Chemistry, vol. 10, no. 12, pp. 1227-1236, 2010.

[2] M. Mahmoudi, M. A. Sahraian, M. A. Shokrgozar, and S. Laurent, "Superparamagnetic iron oxide nanoparticles: promises for diagnosis and treatment of multiple sclerosis," ACS Chemical Neuroscience, vol. 2, no. 3, pp. 118-140, 2011.

[3] M. K. Yu, J. Park, and S. Jon, "Targeting strategies for multifunctional nanoparticles in cancer imaging and therapy," Theranostics, vol. 2, no. 1, pp. 3-44, 2012.

[4] F. Zeinali Sehrig, S. Majidi, S. Asvadi et al., "An update on clinical applications of magnetic nanoparticles for increasing the resolution of magnetic resonance imaging," Artificial Cells, Nanomedicine, and Biotechnology, pp. 1-6, 2015.

[5] C. Rümenapp, B. Gleich, H. G. Mannherz, and A. Haase, "Detection of molecules and cells using nuclear magnetic resonance with magnetic nanoparticles," Journal of Magnetism and Magnetic Materials, vol. 380, pp. 271-275, 2015. 
[6] K. Y. Choi, G. Liu, S. Lee, and X. Chen, “Theranostic nanoplatforms for simultaneous cancer imaging and therapy: current approaches and future perspectives," Nanoscale, vol. 4, no. 2, pp. 330-342, 2012.

[7] K. M. Bennett, J.-I. Jo, H. Cabral, R. Bakalova, and I. Aoki, “MR imaging techniques for nano-pathophysiology and theranostics," Advanced Drug Delivery Reviews, vol. 74, pp. 75-94, 2014.

[8] J. E. Rosen, L. Chan, D.-B. Shieh, and F. X. Gu, "Iron oxide nanoparticles for targeted cancer imaging and diagnostics," Nanomedicine: Nanotechnology, Biology, and Medicine, vol. 8, no. 3, pp. 275-290, 2012.

[9] K. C. Barick, S. Singh, D. Bahadur, M. A. Lawande, D. P. Patkar, and P. A. Hassan, "Carboxyl decorated $\mathrm{Fe}_{3} \mathrm{O}_{4}$ nanoparticles for MRI diagnosis and localized hyperthermia," Journal of Colloid and Interface Science, vol. 418, pp. 120-125, 2014.

[10] M. K. Lima-Tenório, E. A. Gómez Pineda, N. M. Ahmad, H. Fessi, and A. Elaissari, "Magnetic nanoparticles: in vivo cancer diagnosis and therapy," International Journal of Pharmaceutics, vol. 493, no. 1, pp. 313-327, 2015.

[11] B. Jang, H. Kwon, P. Katila, S. J. Lee, and H. Lee, "Dual delivery of biological therapeutics for multimodal and synergistic cancer therapies," Advanced Drug Delivery Reviews, vol. 98, pp. 113-133, 2016.

[12] L. T. Thu Huong, N. H. Nam, D. H. Doan et al., "Folate attached, curcumin loaded $\mathrm{Fe}_{3} \mathrm{O}_{4}$ nanoparticles: a novel multifunctional drug delivery system for cancer treatment," Materials Chemistry and Physics, vol. 172, pp. 98-104, 2016.

[13] C. Song, G.-Y. Wang, and D.-M. Kong, "A facile fluorescence method for versatile biomolecular detection based on pristine $\alpha-\mathrm{Fe}_{2} \mathrm{O}_{3}$ nanoparticle-induced fluorescence quenching," Biosensors and Bioelectronics, vol. 68, pp. 239-244, 2015.

[14] M. Mahmoudi, S. Sant, B. Wang, S. Laurent, and T. Sen, "Superparamagnetic iron oxide nanoparticles (SPIONs): development, surface modification and applications in chemotherapy," Advanced Drug Delivery Reviews, vol. 63, no. 1-2, pp. 2446, 2011.

[15] N. Erathodiyil and J. Y. Ying, "Functionalization of inorganic nanoparticles for bioimaging applications," Accounts of Chemical Research, vol. 44, no. 10, pp. 925-935, 2011.

[16] J. J. Castillo, T. Rindzevicius, C. E. Rozo, and A. Boisen, "Adsorption and vibrational study of folic acid on gold nanopillar structures using surface-enhanced raman scattering spectroscopy," Nanomaterials and Nanotechnology, vol. 5, no. 1, article 29, 2015.

[17] A. Scomparin, S. Salmaso, A. Eldar-Boock et al., "A comparative study of folate receptor-targeted doxorubicin delivery systems: dosing regimens and therapeutic index," Journal of Controlled Release, vol. 208, pp. 106-120, 2015.

[18] A. Krais, L. Wortmann, L. Hermanns et al., "Targeted uptake of folic acid-functionalized iron oxide nanoparticles by ovarian cancer cells in the presence but not in the absence of serum," Nanomedicine: Nanotechnology, Biology, and Medicine, vol. 10, no. 7, pp. 1421-1431, 2014.

[19] L. E. Kelemen, “The role of folate receptor $\alpha$ in cancer development, progression and treatment: cause, consequence or innocent bystander?" International Journal of Cancer, vol. 119, no. 2, pp. 243-250, 2006.

[20] C. Chen, J. Ke, X. Edward Zhou et al., "Structural basis for molecular recognition of folic acid by folate receptors," Nature, vol. 500, no. 7463, pp. 486-489, 2013.

[21] J. Wen, S. Jiang, Z. Chen et al., "Apoptosis selectively induced in BEL-7402 cells by folic acid-modified magnetic nanoparticles combined with $100 \mathrm{~Hz}$ magnetic field," International Journal of Nanomedicine, vol. 9, no. 1, pp. 2043-2050, 2014.

[22] M. Magro, G. Sinigaglia, L. Nodari et al., "Charge binding of rhodamine derivative to $\mathrm{OH}$-stabilized nanomaghemite: universal nanocarrier for construction of magnetofluorescent biosensors," Acta Biomaterialia, vol. 8, no. 6, pp. 2068-2076, 2012.

[23] D. Shi, N. M. Bedford, and H.-S. Cho, "Engineered multifunctional nanocarriers for cancer diagnosis and therapeutics," Small, vol. 7, no. 18, pp. 2549-2567, 2011.

[24] P. Eghbali, H. Fattahi, S. Laurent, R. N. Muller, and Y. M. Oskoei, "Fluorophore-tagged superparamagnetic iron oxide nanoparticles as bimodal contrast agents for MR/optical imaging," Journal of the Iranian Chemical Society, vol. 13, no. 1, pp. 87-93, 2016.

[25] V. S. R. Harrison, C. E. Carney, K. W. Macrenaris, and T. J. Meade, "A multimeric MR-optical contrast agent for multimodal imaging," Chemical Communications, vol. 50, no. 78, pp. 11469-11471, 2014.

[26] B. Banerji, S. K. Pramanik, S. Mandal, N. C. Maiti, and K. Chaudhuri, "Synthesis, characterization and cytotoxicity study of magnetic $\left(\mathrm{Fe}_{3} \mathrm{O}_{4}\right)$ nanoparticles and their drug conjugate," RSC Advances, vol. 2, no. 6, pp. 2493-2497, 2012.

[27] J. Lodhia, G. Mandarano, N. J. Ferris, P. Eu, and S. F. Cowell, "Development and use of iron oxide nanoparticles (Part 1): synthesis of iron oxide nanoparticles for MRI," Biomedical Imaging and Intervention Journal, vol. 6, no. 2, article e12, 2010.

[28] J. Sun, S. Zhou, P. Hou et al., "Synthesis and characterization of biocompatible $\mathrm{Fe}_{3} \mathrm{O}_{4}$ nanoparticles," Journal of Biomedical Materials Research-Part A, vol. 80, no. 2, pp. 333-341, 2007.

[29] S. Karamipour, M. S. Sadjadi, and N. Farhadyar, "Fabrication and spectroscopic studies of folic acid-conjugated $\mathrm{Fe}_{3} \mathrm{O}_{4} @ \mathrm{Au}$ core-shell for targeted drug delivery application," Spectrochimica Acta-Part A: Molecular and Biomolecular Spectroscopy, vol. 148, pp. 146-155, 2015.

[30] S. Sitthichai, C. Pilapong, T. Thongtem, and S. Thongtem, "CMC-coated $\mathrm{Fe}_{3} \mathrm{O}_{4}$ nanoparticles as new MRI probes for hepatocellular carcinoma," Applied Surface Science, vol. 356, pp. 972-977, 2015.

[31] L. Zhao, T.-H. Kim, H.-W. Kim, J.-C. Ahn, and S. Y. Kim, "Enhanced cellular uptake and phototoxicity of Verteporfinconjugated gold nanoparticles as theranostic nanocarriers for targeted photodynamic therapy and imaging of cancers," Materials Science and Engineering C, vol. 67, pp. 611-622, 2016.

[32] T. T. T. N'Guyen, H. T. T. Duong, J. Basuki et al., "Functional iron oxide magnetic nanoparticles with hyperthermia-induced drug release ability by using a combination of orthogonal click reactions," Angewandte Chemie-International Edition, vol. 52, no. 52, pp. 14152-14156, 2013.

[33] T. E. Pylaev, E. K. Volkova, V. I. Kochubey, V. A. Bogatyrev, and N. G. Khlebtsov, "DNA detection assay based on fluorescence quenching of rhodamine B by gold nanoparticles: The optical mechanisms," Journal of Quantitative Spectroscopy and Radiative Transfer, vol. 131, pp. 34-42, 2013.

[34] H. Liu, Y. Wang, H. Li, Z. Wang, and D. Xu, "Luminescent Rhodamine B doped coreeshell silica nanoparticle labels for protein microarray detection," Dyes and Pigments, vol. 98, no. 1, pp. 119-124, 2013.

[35] M. Das, D. Mishra, T. K. Maiti, A. Basak, and P. Pramanik, "Bio-functionalization of magnetite nanoparticles using an aminophosphonic acid coupling agent: new, ultradispersed, iron-oxide folate nanoconjugates for cancer-specific targeting," Nanotechnology, vol. 19, no. 41, Article ID 415101, 2008. 
[36] M. Das, D. Bandyopadhyay, D. Mishra et al., "“Clickable”, trifunctional magnetite nanoparticles and their chemoselective biofunctionalization," Bioconjugate Chemistry, vol. 22, no. 6, pp. 1181-1193, 2011.

[37] M. Calero, L. Gutiérrez, G. Salas et al., "Efficient and safe internalization of magnetic iron oxide nanoparticles: two fundamental requirements for biomedical applications," Nanomedicine: Nanotechnology, Biology, and Medicine, vol. 10, no. 4, pp. 733743, 2014.

[38] A. M. Nyström and K. L. Wooley, "The importance of chemistry in creating well-defined nanoscopic embedded therapeutics: devices capable of the dual functions of imaging and therapy," Accounts of Chemical Research, vol. 44, no. 10, pp. 969-978, 2011. 

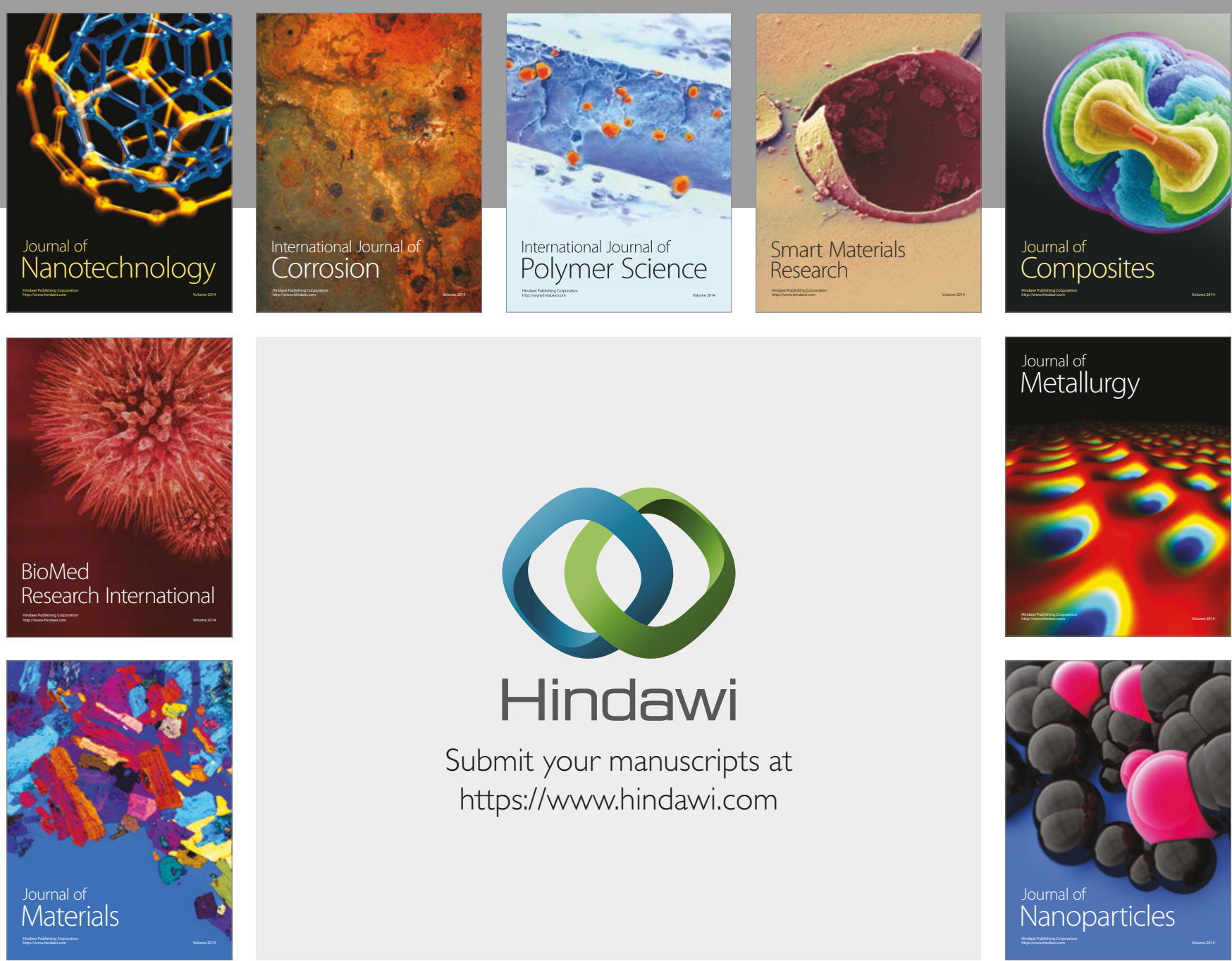

\section{Hindawi}

Submit your manuscripts at

https://www.hindawi.com
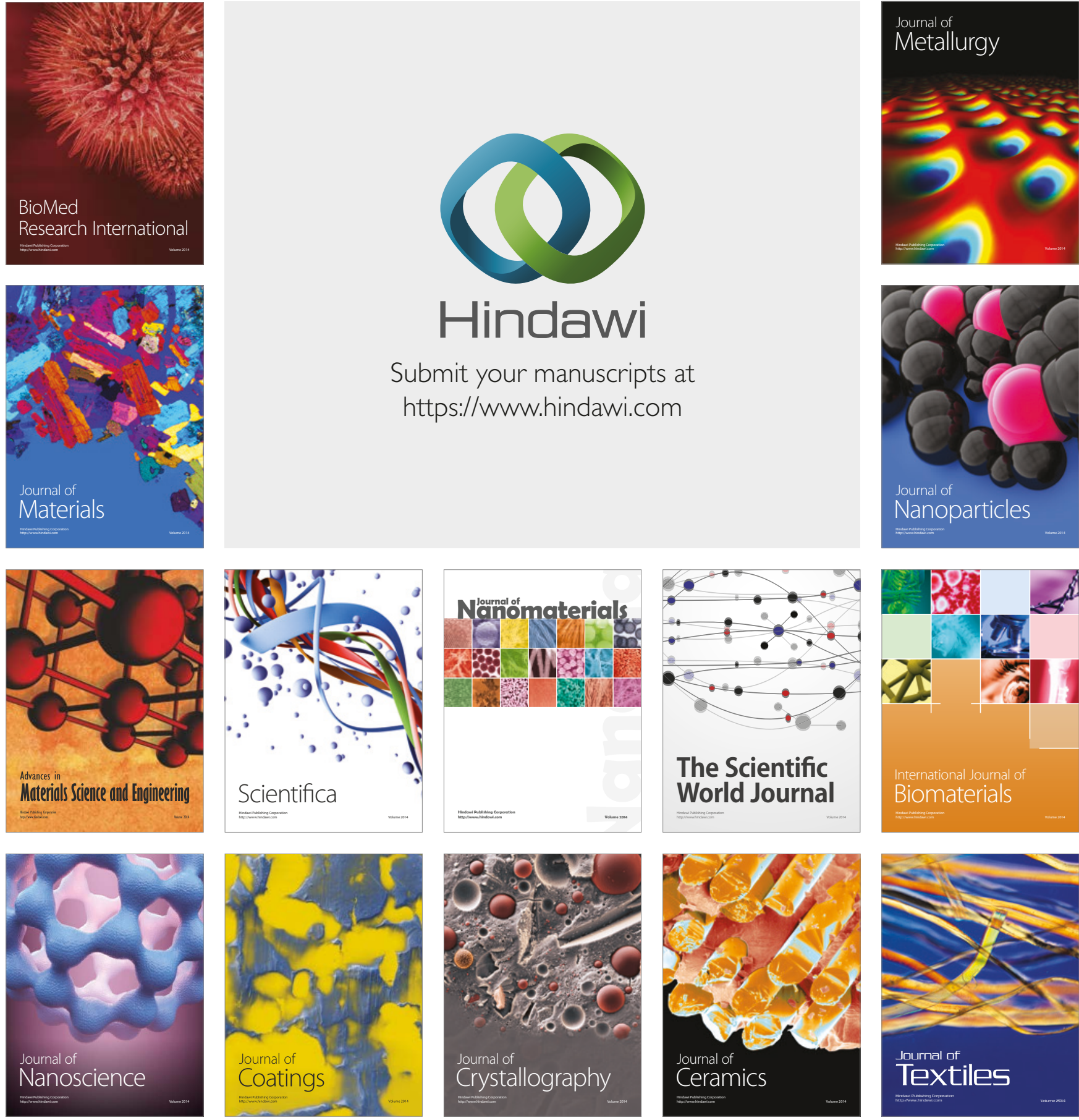

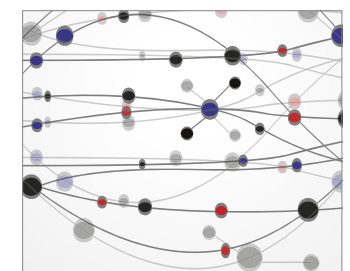

The Scientific World Journal
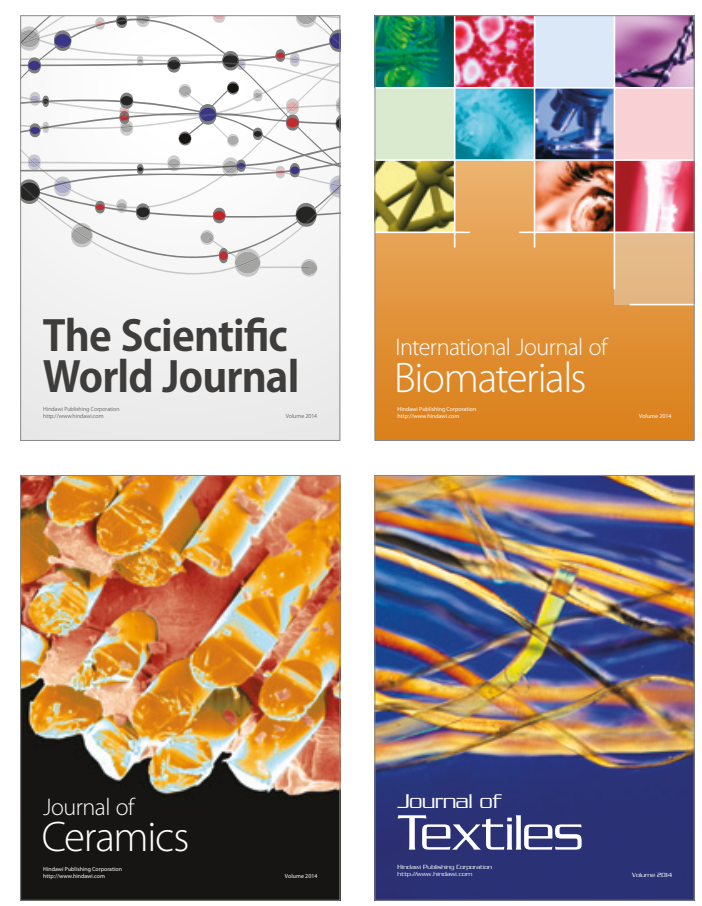